\title{
ASSOCIAÇÃO DE LOGÍSTICA REVERSA DE EMBALAGENS - ASLORE - ANÁLISE DA PERCEPÇÃO DOS SEUS ASSOCIADOS QUANTO À IMPORTÂNCIA E SATISFAÇÃO
}

\author{
E. GAUSMANN ${ }^{1}$ e C. C. DA S. CYRNE ${ }^{2}$ \\ Universidade do Vale do Taquari \\ estela@universo.univates.br ${ }^{1}$
}

Submetido em 21/06/2019 - Aceito em 25/11/2019

DOI: $10.15628 /$ holos. 2020.8751

\section{RESUMO}

A aprovação da Política Nacional de Resíduos Sólidos (PNRS), em 2010, por meio da Lei 12.305/10 culminou de uma articulação tramitada há cerca de vinte anos no Congresso Nacional. Dentre seus instrumentos, destaca-se a Logística Reversa. Um dos mecanismos para a implantação deste processo é o acordo setorial, viabilizado através de contrato entre poder público e fabricantes, importadores, distribuidores ou comerciantes de diferentes produtos. A partir desta orientação instituiu-se em 2015, por meio da FIERGS (Federação das Indústrias do Estado do Rio Grande do Sul) a ASLORE (Associação de Logística Reversa de Embalagens), fator que motivou este estudo a responder o seguinte problema de pesquisa: Qual a importância e o grau de satisfação dos
\end{abstract}

associados da ASLORE em relação aos seus serviços prestados? Desta forma, o objetivo geral foi propor possíveis ações em relação aos serviços prestados pela ASLORE, a partir da avaliação de seus associados, nos aspectos ambientais, legais, sociais e econômicos significativos para esta e seus associados. Quanto aos procedimentos metodológicos, este estudo caracteriza-se como exploratório, descritivo e quantitativo, valendo-se de etapa bibliográfica, pesquisa de campo e estudo de caso. Após as análises, constatou-se que há reconhecimento pela atuação da ASLORE, porém observaram-se descontentamentos. A partir desses aspectos levantados, sugeriram-se ações de intervenção.

PALAVRAS-CHAVE: Política Nacional de Resíduos Sólidos, Logística Reversa, Embalagens, ASLORE.

\section{ASSOCIATION OF REVERSAL PACKAGING LOGISTICS - ASLORE - ANALYSIS OF THE MEMBERS' PERCEPTION OF IMPORTANCE AND SATISFACTION}

\begin{abstract}
The approval of National Policy of Solid Waste (PNRS) in 2010, through of Law 12,305/10 culminated of an articulation that has been running for about twenty years in the National Congress. Among its instruments, the Reverse Logistics stands out. One of the mechanisms for the implementation of this process is the sectorial agreement, attained through a contract between public authorities and manufacturers, importers, distributors or traders of different products. From this orientation the ASLORE (Reverse Logistics of Packaging Association) was established in 2015, through FIERGS (Federation of Industries of the State of Rio Grande do Sul), factor that motivated this study to answer the following research problem: What is the importance and degree of
\end{abstract}

satisfaction of ASLORE members in relation to their services? In this way, the general objective was to propose possible actions in relation to the services provided by ASLORE, based on evaluation of this members, in the significant environmental, legal, social and economic aspects for this and its associates. As for the methodological procedures, this study is characterized as exploratory, descriptive and quantitative, using bibliographical stage, field research and case study. After the analyses, it was verified that there is recognition for the performance that ASLORE, but dissatisfaction was observed. Based on these aspects, interventions were suggested. 


\section{INTRODUÇÃO}

A Lei 12.305, de 2 de agosto de 2010, instituiu a Política Nacional de Resíduos Sólidos, que apresenta não apenas princípios, objetivos e instrumentos, como também os fundamentos do desenvolvimento sustentável e as diretrizes relativas à gestão integrada e ao gerenciamento de resíduos sólidos, incluindo-se os perigosos, as responsabilidades dos geradores e do poder público, bem como seus instrumentos econômicos aplicáveis. Regulamentada pelo Decreto 7.404, de 23 de dezembro de 2010, a Lei Federal 12.305 leva em conta que o resíduo sólido é reutilizável e reciclável, com valor econômico e social, estando sujeitas tanto às pessoas físicas como jurídicas (BRASIL, 2010).

Nesse contexto, destaca-se a Logística Reversa, um dos instrumentos determinados pela PNRS, que tem por objetivo viabilizar o retorno de materiais, peças, embalagens e outros componentes à cadeia produtiva da empresa, garantindo seu descarte adequado ou seu reaproveitamento (LEITE, 2009).

A Lei tem a previsão expressa de que cabe ao consumidor devolver o resíduo do produto após o uso ao distribuidor e ou varejista. Esses, por sua vez, devem devolver ao fabricante e importador, os quais asseguram a destinação final adequada - processo de reciclagem, no caso das embalagens (informação verbal) ${ }^{1}$.

De acordo com o Sistema Nacional de Informações sobre a Gestão dos Resíduos Sólidos (SINIR, 2017), esse sistema é implementado por meio de instrumentos jurídicos contratuais, emitidos pelo poder público, sendo um deles os acordos setoriais. Nesse caso, o fabricante/distribuidor estabelece com a União as diretrizes da Logística Reversa por meio de um contrato, que permite negociar a execução da política pública.

Tendo em vista o disposto na Lei no 12.305 e no Decreto no 7.404, o Ministério do Meio Ambiente tornou público o chamamento de fabricantes, importadores, distribuidores e comerciantes de embalagens e de produtos comercializados em embalagens, através do Edital no 02/2012, publicado em 22 de junho de 2012. O objetivo dessa chamada foi solicitar a elaboração de proposta de acordo setorial para a implementação de sistema de logística reversa de abrangência nacional.

A principal vantagem de participar de um acordo setorial é a liberdade de discussão sobre a regra e política pública de implementação, o que resulta na inteligência da regulação. 0 associado tem o direito de discutir a norma, o sistema, e decidir sobre como implementá-los. Para as organizações que não aderiram ao acordo setorial, no entanto, o governo federal publicou em 23 de outubro de 2017, o Decreto 9.177, a fim de que se cumpra a determinação da Lei (informação verbal) $^{2}$. Em 22 de setembro de 2015, foi assinado um acordo setorial que implantou a Associação

\footnotetext{
${ }^{1}$ Informação verbal fornecida por Fabrício Dorado Soler, no evento Logística Reversa de Embalagens em Geral, em Porto Alegre/RS, em 10 de outubro de 2018.

2 Informação verbal fornecida por Fabrício Dorado Soler, no evento Logística Reversa de Embalagens em Geral, em Porto Alegre/RS, em 10 de outubro de 2018.
} 
de Logística Reversa de Embalagens (ASLORE), com sede localizada em Porto Alegre/RS, nas dependências da Federação das Indústrias do Estado do Rio Grande do Sul (FIERGS).

Partindo-se do intuito de auxiliar na ampliação das intervenções para o cumprimento das determinações da PNRS, em relação à Logística Reversa de resíduos sólidos de embalagens em geral, e considerando a relevância de aspectos ambientais, legais, sociais e econômicos significativos para a ASLORE e seus associados, o presente estudo tomou por referência o conhecimento aplicado por Slack, Chambers e Johnston (2009), que orientam o pesquisador a classificar suas variáveis (neste caso, importância e satisfação) em até quatro possíveis zonas de prioridade: adequada, melhoramento, ação urgente ou excesso. Desta forma, definiu-se o objetivo deste estudo: "Propor possíveis ações em relação aos serviços prestados pela ASLORE, a partir da avaliação de seus associados, nos aspectos ambientais, legais, sociais e econômicos significativos para esta e seus associados."

\section{REVISÃO DA LITERATURA}

O atual nível de consumo, fruto do sistema capitalista, é um dos fatores dos quais as políticas públicas atuais vêm perdendo o controle. A dificuldade atual dos governos não é a criação de leis, mas o processo de execução e acompanhamento, que na maioria dos casos fica a desejar (NASCIMENTO, et al., 2015). Cabe ao governo impulsionar o desenvolvimento social sem prejuízo ao meio ambiente. Seu papel é fundamental nos mercados, dado seu poder de criação e regulamentação de leis, bem como de fiscalização de atividades (ALVES, 2016).

Vista a necessidade de modificarem-se as más condutas exercidas pela sociedade, o que decorre dos elevados custos socioeconômicos e ambientais, o poder público instituiu, após anos de estudos e análises, a Política Nacional de Resíduos Sólidos (PNRS). O objetivo desse programa é enfrentar problemas ambientais, sociais e econômicos relacionados ao manejo inadequado dos resíduos, conforme exposto a seguir.

\subsection{Política nacional dos resíduos sólidos}

A União Europeia (UE) tornou-se precursora na elaboração de mecanismos regulamentares a respeito da Gestão de Resíduos Sólidos (GRS). Essa diretiva determinava que os estadosmembros da UE elaborassem planos para a GRS, a fim de promover a prevenção, reciclagem e reutilização dos resíduos sólidos. Além disso, baseava-se no princípio do "poluidor-pagador", em que os custos da GRS devem ser suportados pelo gerador de resíduos. Desse modo, a UE serviu de referência para diversos países, especialmente o Brasil, com a Política Nacional dos Resíduos Sólidos (OLIVEIRA, 2017).

Neste contexto, para Oliveira (2017) e Nascimento (et al., 2015), a PNRS colocou o Brasil em patamar de igualdade com os países desenvolvidos quanto às normas para a gestão de resíduos sólidos, seguindo assim uma hierarquia de gerenciamento. De acordo com a Sociedade Ponto Verde (2015), entidade privada e sem fins lucrativos que opera desde 1996 em Portugal, as 
empresas produtoras de embalagens são importantes parceiras à sociedade para que se viabilize o processo de reciclagem, pois se comprometem em assegurar as condições necessárias para um ciclo de sustentabilidade constante, contribuindo para o aumento da vida útil dos materiais e para a preservação do ambiente.

No Brasil, a Política Nacional de Resíduos Sólidos foi instituída pelo governo federal em 2 de agosto de 2010 por meio da Lei 12.305, representando o início da regulamentação do setor de resíduos sólidos no Brasil. Conforme Art. 1으 § 1으, estão sujeitas à aplicação da lei todas as pessoas físicas ou jurídicas, de direito público ou privado, responsáveis direta ou indiretamente pela geração de resíduos, bem como as que desenvolvam ações relacionadas à gestão integrada ou ao gerenciamento de resíduos sólidos. Essa normativa não se aplica a materiais radioativos, que dispõe de legislação específica (Brasil, 2010).

Conforme Capítulo 2, Art. 7으, Inciso II, a PNRS estabelece uma hierarquia para as ações no manejo de resíduos sólidos: não geração, redução ou reuso, reciclagem, tratamento dos resíduos sólidos e disposição final ambientalmente adequada dos rejeitos (BRASIL, 2010). Com prazo de vigência indeterminado, a Política Nacional incentiva a prática da coleta seletiva, os sistemas de Logística Reversa, o incentivo à criação e desenvolvimento de cooperativas e outras formas de associação de catadores de materiais recicláveis (BRASIL, 2011).

Mwanza, Mbohwa e Telukdarie (2018) ressaltam que a prática da reciclagem é um importante fator para a redução de custos da produção, por gerar renda e criação de empregos, proporcionando, principalmente, solução para a diminuição de materiais depositados em aterros. Muitas empresas de manufatura motivam-se para recuperar materiais da cadeia de abastecimento, pela perspectiva de aproveitamento sustentável desses materiais. A reciclagem foi implementada para diferentes materiais de embalagem em muitos países, com o intuito de reduzir a quantidade de resíduos e seu impacto ambiental relacionado (GEUEKE; GROH; MUNCKE, 2018).

Bartholomeu e Caixeta-Filho (2017) colocam que, sob a coordenação do Ministério do Meio Ambiente, o Plano Nacional de Resíduos Sólidos foi criado com a proposta de ser atualizado a cada quatro anos. Para sua execução, contava-se com a responsabilidade de estados e municípios na elaboração de seus próprios planos, correndo o risco de não receber acesso a recursos da União para empreendimentos e serviços de gestão dos resíduos sólidos se não implementado. Para os municípios, os desafios para alterar a realidade são diversos, ressaltando-se, porém, a importância da capacidade de planejamento e de gestão mais eficiente dos serviços públicos.

\subsection{A Logística Reversa como instrumento da PNRS}

Os primeiros estudos sobre Logística Reversa foram registrados entre as décadas de 1970 e 1980, tendo sido seu principal foco relacionado ao retorno de bens para o processamento e reciclagem dos materiais, servindo, ainda, como canais de distribuição reversos (HERNÁNDEZ, et al., 2012).

A PNRS prevê, no Art. 3ำ, inciso XII, a definição de Logística Reversa como instrumento de desenvolvimento econômico e social, caracterizado pelo conjunto de ações, procedimentos e 
meios destinados a viabilizar a coleta e a restituição dos resíduos sólidos ao setor empresarial, para reaproveitamento em seu ciclo ou em outros ciclos produtivos, ou ainda para distinta destinação final ambientalmente adequada (SINIR, 2017).

Para que a Logística Reversa seja corretamente implementada, é necessária a celebração de um acordo setorial (Art. 15, inciso I do Decreto 7.404/2010), que representa ato de natureza contratual firmado entre poder público e fabricantes, importadores, distribuidores ou comerciantes, tendo em vista a implantação da responsabilidade compartilhada pelo ciclo de vida do produto. Nos parâmetros da responsabilidade compartilhada, todos os atores envolvidos comprometem-se com seu gerenciamento, foco no reuso, redução e reciclagem dos materiais, bem como a minimização da disposição dos rejeitos em sistemas de tratamento final (RIBEIRO; MORELLI, 2009; BRASIL, 2010).

O acordo setorial referente a "Embalagens em Geral" foi assinado em 25 de novembro de 2015, entre as Associações (na qualidade de representantes das empresas) e o Ministério do Meio Ambiente, com o objetivo de garantir a destinação ambientalmente adequada das embalagens que compõem a fração seca dos resíduos sólidos urbanos, tais como papel, papelão, plástico, metal, vidro e embalagem cartonada longa vida (ASLORE, 2018).

O estudo da literatura permite considerar que a responsabilização ambiental nas esferas civil, penal e administrativa contribui sobremaneira para reforçar a almejada cooperação entre os atores do sistema de logística reversa, visando a celebração do acordo setorial e minimizando o risco de uma gestão inadequada dos resíduos sólidos, que resulte em dano ao meio ambiente, crime e multa administrativa.

Dentre as espécies de resíduos, destacam-se as embalagens, que sob uma ótica abrangente, representa um sistema que resulta da integração de arte, ciência e técnicas de produção, a fim de proporcionar condições ótimas de transporte, armazenagem, distribuição, venda e consumo. Também é vista por alguns como um simples ato de embalar, ou, ainda, como o elemento ou conjunto de elementos que envolvem o produto, com a função de protegê-lo e preservá-lo durante sua movimentação até chegar ao consumidor final (MOURA; BANZATO, 1997).

De acordo com Carvalho (2008), é possível a utilização dos seguintes tipos de materiais para a composição de uma embalagem:

- Papelão, na forma de caixas (utilizado para embalagens descartáveis ou retornáveis);

- Sacos de papel (geralmente descartáveis);

- Metal (são retornáveis, utilizados para materiais pesados ou contaminados);

- Madeira e derivados (preferível para embalagens retornáveis);

- Plástico, na forma de caixas (para embalagens retornáveis);

- Fibras sintéticas flexíveis (usadas para materiais a granel);

- Fibra de papel, na forma de tambores (passíveis de retorno). 


\subsection{Resíduos Sólidos}

Os resíduos sólidos gerados pelas mais variadas atividades humanas não estão sendo descartados de forma apropriada, o que se constitui um grave problema para a sociedade, em vista da iminência de acidentes ambientais. Tais acidentes podem ocorrer em razão do descarte indevido de produtos químicos nas vias públicas, nos rios, nos mares. Além disso, a disposição indevida desses químicos sob o solo, o seu armazenamento inadequado em indústrias, galpões de armazenamento, terrenos baldios, ou ainda pela liberação de gases no ar, colocam em risco a saúde pública e o meio ambiente.

A Lei 12.305/10 define, em seu Art. 3, Inciso XVI, os resíduos sólidos como:

Material, substância, objeto ou bem descartado resultante de atividades humanas em sociedade, a cuja destinação final se procede, se propõe proceder ou se está obrigado a proceder, nos estados sólido ou semissólido, bem como gases contido sem recipientes e líquidos cujas particularidades tornem inviável os lançamentos na rede pública de esgotos ou em corpos d'água, ou exijam para isso soluções técnica ou economicamente inviáveis em face da melhor tecnologia disponível (BRASIL, 2010).

Para que se obtenha diminuição dos impactos ambientais e garantia de saúde pública, é essencial reduzir a produção dos resíduos sólidos. Quando gerados, é fundamental que sejam classificadas e encaminhadas corretamente a locais de tratamento, como reciclagem, compostagem para o caso de resíduos orgânicos, reaproveitamento ou ainda disposição final, como aterros sanitários ou industriais (MOTA, 2003; SOLER, 2014).

No que se refere à responsabilidade ambiental, o Art. 51 da PNRS estabelece que a ação ou omissão das pessoas físicas ou jurídicas que importe inobservância aos preceitos da PNRS ou de seu regulamento sujeita os infratores às sanções previstas em lei, em especial às fixadas na Lei Federal n. 9.605/1998, que dispõe sobre as sanções penais e administrativas derivadas de condutas e atividades lesivas ao meio ambiente (Lei de Crimes Ambientais). O seu regulamento (Decreto Federal n. 6.514/2008) dispõe sobre as infrações e sanções administrativas ao meio ambiente e estabelece o processo administrativo federal para apuração dessas infrações (BRASIL, 2010).

Com base no exposto, entende-se que estas informações confirmam o dever de todos os atores envolvidos no processo de geração de resíduos sólidos, bem como a possibilidade de aplicações penais. A implementação da Política Nacional de Resíduos Sólidos representou um marco regulatório para diretrizes de gestão em todo o país, estabelecendo responsabilidades à sociedade, à iniciativa privada e ao poder público.

\section{METODOLOGIA}

Dentre as unidades metodológicas, o positivismo destaca-se como uma corrente de pensamento em que a ciência é resultado da experiência. A abordagem positivista é explicitada no presente estudo à medida que os objetivos específicos foram desenvolvidos. Triviños (1987), bem como Collins e Hussey (2005) colocam que o positivismo se concentra em descobrir as relações entre as coisas e os fatos, podendo-se compreender, no âmbito deste trabalho, a aplicação das 
instruções regulamentadas em Lei pela ASLORE, e em especial, as ações e normativas da prática de Logística Reversa.

Quanto à natureza, o estudo valeu-se de uma etapa exploratória, evidenciada pela fase de levantamento bibliográfico para aprofundamento dos conceitos e normas existentes, bem como pela aplicação de entrevista com a responsável técnica da ASLORE. Em relação aos objetivos, o estudo é do tipo descritivo, pois "busca a verificação de fatos ocorridos num determinado período de tempo, sem manipular as variáveis que as ocasionam" (MARTINS JUNIOR, 2009, p. 88).

Para a realização da pesquisa com os associados da ASLORE, aplicou-se um questionário com catorze perguntas, do tipo fechadas, via Google Forms, com o objetivo de captar a percepção das empresas e entidades associadas acerca de abordagens nas áreas ambiental, econômica, legal e social, validadas como importantes para a Associação. Para cada uma delas, coube ao respondente informar o grau de importância e satisfação atribuídos, indicando nota de 1 (um) a 9 (nove), sendo um "muito importante" ou "muito satisfeito" e nove "nada importante" ou "muito insatisfeito". A técnica da escala de nove pontos é validada na obra de Slack, Chambers e Johnston (2009).

Quanto à abordagem do problema, esta pesquisa classifica-se como quantitativa. Já em relação aos procedimentos técnicos, contou com etapa bibliográfica e pesquisa de campo, aplicada aos partícipes da Associação de Logística Reversa de Embalagens, entre junho e julho de 2018. Os associados entrevistados são pessoas jurídicas de direito público (órgão governamentais) ou privado (sindicatos, indústrias ou associações). As indústrias possuem a obrigatoriedade de estar filiadas aos seus respectivos sindicatos patronais.

A presente pesquisa também se classifica como estudo de caso, em virtude de tomar como objeto de análise a ASLORE, partindo da verificação do grau de importância e satisfação que seus associados atribuem a questões na área ambiental, econômica, legal e social.

Quanto à população, é formada pelo quadro de associados da ASLORE. No momento da aplicação da pesquisa, 50 (cinquenta) empresas ou entidades (sindicatos e associações), oriundas de 29 municípios do Rio Grande do Sul integravam o quadro de associados da entidade. As respostas válidas obtidas somaram 32 , representando $64 \%$ do quadro de associados.

Quanto à análise de dados, elaborou-se matriz importância $(X)$ versus satisfação $(Y)$, por meio do Gráfico de Dispersão, disponibilizado pelo Microsoft Excel, que também possibilitou a manipulação de fórmulas e elaboração de tabelas. O cruzamento das duas variáveis marcou um ponto no gráfico, indicando nos possíveis quadrantes, conforme a literatura, a zona em que cada questão se classificou (zona de excesso, zona adequada, zona de melhoramento ou zona de ação urgente).

Slack, Chambers e Johnston (2009) conceituam as zonas de prioridade da seguinte forma:

- zona adequada: os fatores competitivos são considerados satisfatórios;

- zona de melhoramento: está abaixo da zona de aceitabilidade, fazendo com que qualquer fator nessa zona seja passível de melhoramento; 
- zona de ação urgente: fatores importantes para o cliente, porém o desempenho está inferior ao do concorrente. Indicado melhoramento imediato;

- zona de excesso: são fatores de alto desempenho, mas sem importância para o cliente. Necessário analisar se recursos empreendidos neste campo podem ser melhores aplicados em outra demanda.

Tomando-se por base os critérios acima, as respostas obtidas permitiram a elaboração de matriz conforme a Figura 1, cujos resultados alocaram-se nas respectivas zonas de prioridade.

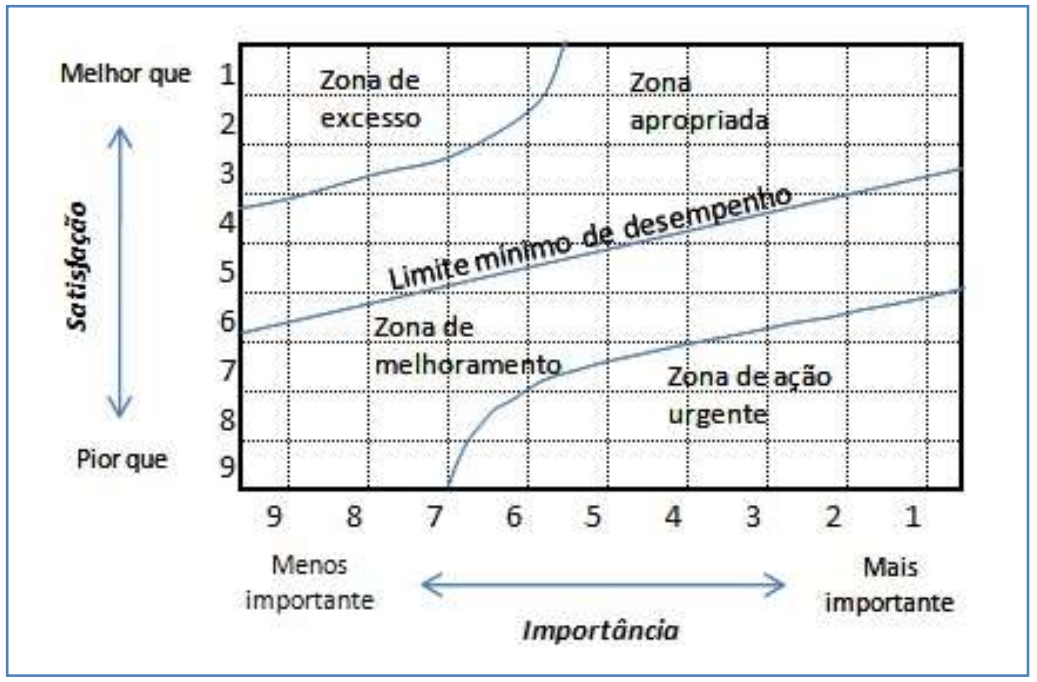

Figura 1: Zonas de prioridade na matriz importância x satisfação

Este estudo se limita ao levantamento de percepções dos associados da ASLORE, não sendo considerados outros envolvidos na cadeia da Logística Reversa, como catadores, cooperativas, recicladores, membros do acordo setorial ou mesmo da diretoria da Associação. Restringe-se, também, às ações de Logística Reversa nas categorias ambiental, econômica, legal e social de embalagens pós-consumo, conforme determina o Estatuto da ASLORE, não estando direcionado aos demais itens mencionados no Artigo 33 da Lei 12.305/10, que relaciona os materiais obrigados a estruturar e implementar sistemas de Logística Reversa (agrotóxicos, pilhas e baterias, pneus, óleos lubrificantes, seus resíduos e embalagens, lâmpadas fluorescentes, produtos eletroeletrônicos e seus componentes).

\section{RESULTADOS E DISCUSSÕES}

As questões abordadas ao quadro de associados da ASLORE podem ser conferidas na Tabela 1, que serviram como base para a verificação da importância e satisfação atribuídos às categorias ambiental, econômica, legal e social. 
Tabela 1: - Questões fechadas abordadas por categoria

\begin{tabular}{|c|c|}
\hline AMBIENTAL & $\begin{array}{l}\text { 1. Quanto à parceria indústria/comércio com o objetivo de consolidar os } \\
\text { pontos de entrega voluntária (PEV), orientada pela ASLORE } \\
\text { 2. Quanto à realização de ações pela ASLORE para orientar sobre os } \\
\text { materiais utilizados na fabricação de embalagens e o estímulo à prática } \\
\text { da reciclagem }\end{array}$ \\
\hline ECONÔMICA & $\begin{array}{l}\text { 3. Quanto à clareza e ao conhecimento de sua empresa sobre a } \\
\text { disponibilização de recursos/linhas de crédito para a aplicação na } \\
\text { Logística Reversa e reciclagem das embalagens pós-consumo, em função } \\
\text { das orientações prestadas pela ASLORE } \\
\text { 4. Quanto ao investimento da ASLORE para a aquisição de novos } \\
\text { equipamentos para as cooperativas de catadores }\end{array}$ \\
\hline LEGAL & $\begin{array}{l}\text { 5. Quanto aos esclarecimentos prestados pela ASLORE sobre a insuficiência } \\
\text { de associar-se e aderir ao Acordo Setorial da Coalizão Empresarial como } \\
\text { forma de atender aos requisitos legais dos Estados e Municípios } \\
\text { 6. Quanto às orientações fornecidas pela ASLORE sobre a legislação } \\
\text { ambiental aplicável às atividades de Logística Reversa eà Política Nacional } \\
\text { de Resíduos Sólidos (PNRS) } \\
\text { 7. Quanto à representação que a ASLORE desempenha do seu quadro de } \\
\text { associados no que diz respeito ao Acordo Setorial das Embalagens em } \\
\text { Geral (desconsiderando-se impactos ambientais ou outros aspectos não } \\
\text { relacionados ao mencionado Acordo), perante o Ministério do Meio } \\
\text { Ambiente e demais órgãos de poder público } \\
\text { 8. Quanto às orientações fornecidas pela ASLORE sobre as vantagens das } \\
\text { empresas exercerem sua responsabilidade compartilhada com a } \\
\text { implementação da Logística Reversa das embalagens } \\
\text { 9. Quanto ao esclarecimento sobre as diretrizes do Acordo Setorial de } \\
\text { Embalagens, em atendimento à PNRS } \\
\text { 10. Quanto às vantagens de a ASLORE ser membro da Coalizão Empresarial }\end{array}$ \\
\hline SOCIAL & $\begin{array}{l}\text { 11. Em relação à responsabilidade da ASLORE em organizar, desenvolver, } \\
\text { acompanhar e oferecer suporte a outros programas, pesquisas e projetos } \\
\text { de viabilização da PNRS } \\
\text { 12. Quanto à forma como a ASLORE se posiciona para contribuir com ações } \\
\text { direcionadas à educação, capacitação profissional, empreendedorismo e } \\
\text { aumento da renda de catadores } \\
\text { 13. Quanto à contribuição das ações desenvolvidas pela ASLORE para a } \\
\text { redução da exclusão social, melhoria da remuneração dos catadores e a } \\
\text { melhoria da produtividade das cooperativas } \\
\text { 14. Quanto aos resultados do diagnóstico técnico elaborado pela ASLORE, } \\
\text { disponibilizados internamente aos associados }\end{array}$ \\
\hline
\end{tabular}

A identificação da média das respostas na matriz importância $x$ satisfação constatou que três questões foram enquadradas na zona adequada (2, 10 e 13), equivalente a $22 \%$ das respostas obtidas, e onze questões foram enquadradas na zona de melhoramento $(1,3,4,5,6,7,8,9,11$, 12 e 14), somando-se os $78 \%$ restantes, sem registro de pontuação para a zona de excesso ou ação urgente. Tais informações podem ser evidenciadas na Figura 2 e Tabela 2, conforme demonstrado a seguir. 


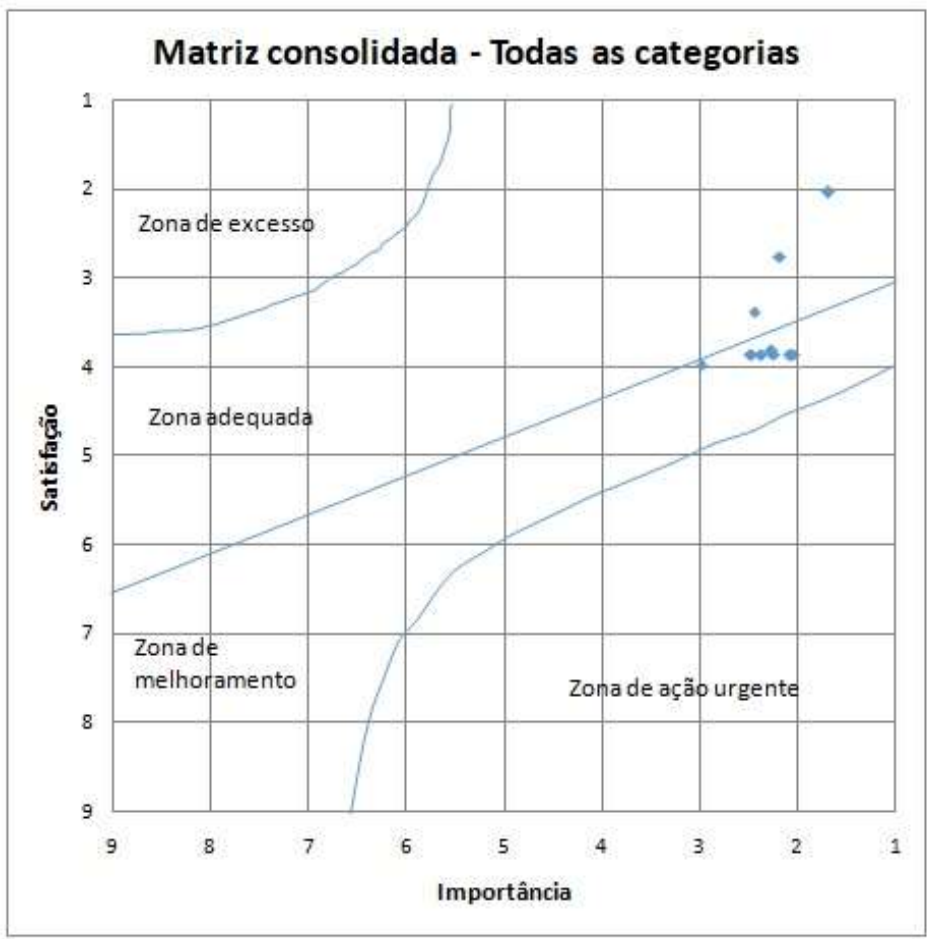

Figura 2: Matriz consolidada

Tabela2: Classificação das respostas por zona

\begin{tabular}{l|ll}
\hline \multicolumn{1}{c|}{ Zona adequada } & \multicolumn{2}{c}{ Zona de melhoramento } \\
\hline Questão 2 - Ambiental & Questão 1 - Ambiental & Questão 8 - Legal \\
Questão 10 - Legal & Questão 3 - Econômica & Questão 9 - Legal \\
Questão 13 - Social & Questão 4 - Econômica & Questão 11 - Social \\
& Questão 5 - Legal & Questão 12 - Social \\
& Questão 6 - Legal & Questão 14 - Social \\
& Questão 7 - Legal & \\
\hline
\end{tabular}

A categoria ambiental contou com melhor média de importância na questão dois $(2,44)$, obtendo médias próximas de satisfação nas questões um e dois. O desvio padrão da média de importância foi menor que o desvio padrão da média de satisfação, demonstrando que há mais opinião semelhante quanto à importância do que quanto à satisfação.

Na categoria econômica, a questão quatro evidenciou melhor média de importância e satisfação, apresentando êxito no primeiro critério, quando comparado ao segundo. Porém, vale ressaltar que o intervalo entre a média obtida na importância $(2,09)$ e a satisfação $(3,85)$ é aproximadamente o dobro. O coeficiente de variação da satisfação $(0,53)$ é menor que o da importância $(0,71)$, o que indica mais homogeneidade na percepção dos respondentes em relação à satisfação.

A questão três classificou-se na zona de melhoria, obtendo média de 3,97 e desvio padrão de 1,53 na satisfação. Dos 32 respondentes, 14 retornaram nota igual ou acima de cinco para o 
nível de satisfação deste item (clareza e conhecimento sobre a disponibilização de recursos/linhas de crédito para a aplicação na Logística Reversa e reciclagem das embalagens), fato que evidencia a necessidade de disponibilizar acesso, orientação e fontes de consulta aos associados sobre como proceder e estimular novas ações para a reciclagem, tanto em relação a possíveis parcerias como na própria empresa.

Tratando-se da categoria legal, a questão 10 apresentou o melhor desempenho da pesquisa, uma vez que $53 \%$ dos entrevistados classificaram-na no item na zona adequada para os critérios importância e satisfação. Contou ainda com o menor índice de desvio padrão nos dois aspectos, se consideradas as quatro categorias, revelando que o item "vantagens de a ASLORE ser membro da Coalizão Empresarial" é o de maior importância e satisfação em relação a todos os outros abordados na pesquisa. Ainda, foi o tópico de menor desvio padrão, confirmando a uniformidade da opinião.

Em relação à categoria social, a questão 14 (diagnóstico técnico) foi a que apresentou melhor resultado na média de importância $(2,06)$, bem como menor desvio padrão $(1,41)$, demonstrando percepções próximas entre os entrevistados. Porém, a satisfação para este item equivale a 3,85, ou seja, há disparidade. Sendo assim, sugere-se elaborar o referido relatório com maior detalhamento, apresentando notas explicativas, gráficos, demonstrativos, fotografias e indicação de referências para consulta. Já a média de satisfação com melhor desempenho relaciona-se à questão 13 , que atingiu nota 2,76 e desvio padrão de 1,71.

Conforme a manifestação dos associados, o item considerado mais importante de toda a pesquisa é a questão 10, corresponde à categoria legal que se refere à vantagem de a ASLORE ser membro da Coalizão Empresarial (média 1,68 e desvio padrão 1,15). Esse ponto também revela a maior satisfação dos respondentes, com média equivalente a 2,03 e desvio padrão 1,27. Apesar de a maioria dos participantes da pesquisa atribuir nota um, dois ou três ao critério satisfação, duas pessoas manifestaram nota cinco e sete, não havendo uniformidade de opinião. Ainda assim, estas manifestações classificam a questão 10, supracitada, na zona adequada.

O resultado obtido na questão 10 é reiterado por outra questão da categoria legal, a de número nove, que informa o segundo item com melhor atribuição de nota ao quesito importância, "esclarecimento sobre as diretrizes do Acordo Setorial de Embalagens, em atendimento à PNRS". O desvio padrão desta questão equivale a 1,77 , contudo destacam-se a média obtida no quesito satisfação, 3,85, e seu desvio padrão, 2,05. Esses resultados demonstram que obter informações acerca do acordo setorial é muito importante para o associado da ASLORE, mas a maioria não está satisfeita com as ações realizadas neste sentido. Considerado o desvio padrão, pode-se chegar a uma nota de 5,90 em satisfação, o que representa um significativo descontentamento, mas não suficiente para classificar a questão na zona de ação urgente, conforme modelo validado por Slack, Chambers e Johnston (2009).

Já a terceira melhor média relacionada à importância foi obtida na questão 14, da categoria social, que está ligada aos resultados do diagnóstico técnico elaborado pela ASLORE, disponibilizados internamente aos associados. Vale destacar que, apesar de ser o terceiro aspecto mais importante, o nível de satisfação é baixo, visto que o retorno representa média de 3,85, 
podendo chegar a 5,90 quando analisado o desvio padrão. Essa manifestação permite constatar que cabe à ASLORE reavaliar as informações que são disponibilizadas aos seus associados, procurando ser mais clara, acessível e significativa.

A segunda melhor média para o critério satisfação foi atribuída à categoria social, no quesito "contribuição das ações desenvolvidas pela ASLORE para a redução da exclusão social, melhoria da remuneração dos catadores e a melhoria da produtividade das cooperativas". Nesse item, obteve-se média equivalente a 2,76 e desvio padrão 1,71, que atrelado a uma boa média também no quesito importância classificaram a questão 13 na zona adequada.

A terceira classificação na zona adequada se deu na categoria ambiental, questão número dois, para o quesito "realização de ações pela ASLORE para orientar sobre os materiais utilizados na fabricação de embalagens e o estímulo à prática da reciclagem". Nesse item, obteve-se média de importância equivalente a 2,44 e de satisfação igual a 3,38. Uma vez evidenciado que a satisfação está aquém da importância atribuída, sugere-se que, mesmo que este aspecto esteja na zona adequada, a ASLORE atente para o aperfeiçoamento das ações relacionadas à orientação sobre quais materiais podem ser utilizados, estimulando a reciclagem.

Em suma, constata-se que os três aspectos mais importantes para os respondentes, de acordo com a média obtida, são:

- vantagens de a ASLORE ser membro da Coalizão Empresarial;

- esclarecimento sobre as diretrizes do Acordo Setorial de Embalagens, em atendimento à PNRS;

- resultados do diagnóstico técnico elaborado pela ASLORE, disponibilizados internamente aos associados.

Já os três aspectos com maior satisfação segundo a percepção dos respondentes, a partir da média obtida, referem-se a:

- vantagens de a ASLORE ser membro da Coalizão Empresarial;

- contribuição das ações desenvolvidas pela ASLORE para a redução da exclusão social, melhoria da remuneração dos catadores e a melhoria da produtividade das cooperativas;

- realização de ações pela ASLORE para orientar sobre os materiais utilizados na fabricação de embalagens e o estímulo à prática da reciclagem.

A partir dessa análise, é possível afirmar que os associados estão satisfeitos com um dos critérios mais importantes, classificado como atributo legal, referente às vantagens de a ASLORE ser membro da Coalizão Empresarial.

Levando em consideração as questões que os respondentes atribuíram maior importância, têm-se a de número quatro, da categoria econômica, que referente ao investimento da ASLORE para a aquisição de novos equipamentos para as cooperativas de catadores. Esse item obteve média 2,09 em importância e 3,85 em satisfação, ou seja, é importante, mas parte dos associados 
não está satisfeito.

Conforme a assessora da ASLORE, 40\% da arrecadação são transferidos para a Associação Nacional dos Catadores e Catadoras de Materiais Recicláveis (ANCAT) e os outros 60\% são revertidos às cooperativas de catadores no RS para a aquisição de equipamentos. A contribuição dos associados é definida a partir da quantidade de embalagens geradas (valor estipulado por tonelada). Dada a média obtida na satisfação e a classificação na zona de melhoramento, sugerese que a ASLORE reavalie como e quais informações estão sendo disponibilizadas ao seu quadro de associados, para que estes percebam de forma clara as ações executadas em favor das cooperativas de catadores.

As mesmas médias (2,09 para importância e 3,85 para satisfação) foram atribuídas para a questão oito, da categorial legal, quanto às orientações fornecidas pela ASLORE sobre as vantagens de as empresas exercerem sua responsabilidade compartilhada com a implementação da Logística Reversa das embalagens. Nesse sentido, dentre os objetivos listados pela Lei 12.305/10 para a implantação da responsabilidade compartilhada, observa-se o Inciso I do Art. 30, parágrafo único, que orienta a compatibilização de interesses entre os agentes econômicos e sociais e os processos de gestão empresarial e mercadológica com os de gestão ambiental, para o desenvolvimento de estratégias sustentáveis.

O estabelecimento de parcerias e atitude na execução de responsabilidades assumidas, - que vai ao encontro do princípio da responsabilidade compartilhada, facilita a implementação de ações com resultados positivos a todos os envolvidos na cadeia. Em observância às respostas cedidas pelos entrevistados, quando se constata relativa insatisfação, sugere-se que a ASLORE esclareça as vantagens de participar do processo de responsabilidade compartilhada, entre as quais está a identificação de alternativas para a garantia da sustentabilidade e a harmonização nos processos de gestão empresarial e mercadológica com os de gestão ambiental. Tais ações podem se propostas por meio de momentos de sensibilização, envio de e-mails instrutivos ou cartas aos gestores, ou ainda com textos explicativos nos relatórios de atividades.

Na sequência, a questão com maior importância atribuída foi a de número seis, da categoria legal (média 2,26 para importância e 3,82 para satisfação), quanto às orientações fornecidas pela ASLORE sobre a legislação ambiental aplicável às atividades de Logística Reversa e à Política Nacional de Resíduos Sólidos (PNRS).

Sendo a ASLORE resultante de acordo setorial para a implantação da prática da Logística Reversa, em consonância com as diretrizes da PNRS, é fundamental a Associação certificar-se de que seus membros conheçam claramente suas obrigações legais. Por tal razão, sugere-se a elaboração de cartilha com esclarecimentos a respeito das obrigações regidas pela Lei e como pode-se aperfeiçoar as atividades realizadas nos processos produtivos.

A questão sete, também da categoria legal, referiu-se à representação que a ASLORE desempenha do seu quadro de associados, relativo ao Acordo Setorial das Embalagens em Geral (desconsiderando-se impactos ambientais ou outros aspectos não relacionados ao mencionado 
Acordo) perante o Ministério do Meio Ambiente e demais órgãos de poder público. Nesse quesito, obteve-se média de importância equivalente a 2,24 e de satisfação igual a 3,85. Atribuído o desvio padrão, a satisfação pode chegar à média de 5,90, o que evidencia a atenção necessária neste sentido. Para os associados, a representação que a ASLORE desempenha perante o Ministério do Meio Ambiente e demais órgãos poderia ser melhor. Por esta razão, entende-se que cabe à Associação a análise de quais aspectos estão gerando eventual descontentamento, levantamento de situações particulares que possam não ter recebido o retorno esperado, esclarecimento de qual o real papel da ASLORE na resolução de impasses jurídicos de seus associados, ou ainda, reuniões, workshops ou oficinas para esclarecimentos acerca de instâncias jurídicas.

Finalizando a abordagem da categoria legal, a questão cinco obteve média 2,38 em importância e 3,85 em satisfação, e referiu-se aos esclarecimentos prestados pela ASLORE sobre a insuficiência de se associar e aderir ao acordo setorial da Coalizão Empresarial como forma de atender aos requisitos legais dos Estados e Municípios. Observa-se que, nesse sentido, uma mudança de posicionamento seria adequada, visto que os associados demonstram não haver clareza quanto a que ações deveriam desempenhar além de ser sócio da ASLORE, que segue as diretivas do acordo setorial existente para a prática da Logística Reversa e cumprimento das questões legais.

Tendo em vista que o foco é o esclarecimento de informações, sugere-se também inserir na cartilha anteriormente sugerida a disponibilização de espaço para esclarecimentos no relatório anual ou na web site da ASLORE, e, ainda, o esclarecimento de dúvidas em oportunidades como assembleias, reuniões ou outros eventos presenciais.

A próxima pergunta com melhor média de importância foi a de número 12 , da categoria social, que atingiu média de importância igual a 2,38 e de satisfação igual a 3,85. No referido item avaliou-se como a ASLORE se posiciona para contribuir com ações direcionadas à educação, à capacitação profissional, ao empreendedorismo e ao aumento da renda de catadores. Dada a percepção dos associados, sugere-se à ASLORE maior perspicuidade na abordagem das ações realizadas nesse sentido, enfatizando seu compromisso social com a garantia da qualidade de vida dos catadores, o que é fundamental para a garantia do sucesso da Logística Reversa.

Por fim, na categoria social, a questão 11 indagou quanto à responsabilidade da ASLORE em organizar, desenvolver, acompanhar e oferecer suporte a outros programas, pesquisas e projetos de viabilização da PNRS. Nesse item, obteve-se média de 2,47 em importância e 3,85 em satisfação. Dada a classificação na zona de melhoramento, sugere-se à ASLORE que invista em novas ações com este compromisso, a fim de potencializar resultados e garantir sua responsabilidade social no envolvimento com atividades que propulsionem o cumprimento das orientações previstas na Política Nacional.

Classificada na categoria ambiental, a pergunta número 1 questionou sobre a parceria indústria/comércio, com o objetivo de consolidar os pontos de entrega voluntária (PEV), orientada pela ASLORE. Em tal tópico obteve-se média 2,47 em importância e 3,85 em satisfação. Considerada a média obtida no quesito satisfação, sugere-se à ASLORE criar novas formas de abordagem quanto às orientações fornecidas para que se utilize este sistema, incentivando a 
participação de indústria e comércio nas ações de conscientização da população.

A pergunta com menor importância e menor satisfação foi a de número 3, integrante da categoria econômica, que se refere à clareza e ao conhecimento da empresa sobre a disponibilização de recursos/linhas de crédito para a aplicação na Logística Reversa e reciclagem das embalagens pós-consumo, em função das orientações prestadas pela ASLORE. Apesar de não apresentar relevância significativa, a questão classificou-se na zona de melhoramento. Sugere-se à ASLORE elaborar plano de benefícios e criar novas alternativas de divulgação, visto que há relevância na temática dada sua menção na Lei.

Verifica-se semelhança nas respostas atribuídas para o quesito satisfação, visto que, das 14 perguntas aplicadas, nove finalizaram com média 3,85, diferente do atributo importância que teve variações. Observa-se que, dos 32 respondentes, 11 atribuíram as mesmas notas no quesito satisfação, repetidamente, sendo elas entre cinco e nove. Tal atitude pode ser manifestação de descontentamento, ou ainda, desmotivação para responder o questionário.

A partir das respostas obtidas, evidencia-se que, na opinião dos associados, a ASLORE vem desenvolvendo trabalho com ações positivas, ressaltando-se, porém, a necessidade de reavaliação de atividades desenvolvidas, que repercutam em maior aproximação aos associados, esclarecimentos de dúvidas, procedimentos, exigências da lei e ações a serem adotadas nas empresas.

A ASLORE poderia ainda elaborar plano de aproximação ao poder público (estado e municípios), para que esses atuem mais enfaticamente como apoiadores no desafio de cumprir a Política Nacional de Resíduos Sólidos. Com isso, objetiva-se mitigar impactos ambientais, diminuir a geração de resíduos, aumentar a renda de famílias de catadores, controlar a destinação do lixo para aterros sanitários e facilitar ao setor empresarial o cumprimento da sua obrigação na responsabilidade compartilhada.

Por fim, convém referir que, por vezes, quem respondeu o questionário não foi o proprietário, o que pode ter influenciado na percepção sobre o envolvimento com as ações da ASLORE.

\section{CONCLUSÃO}

A execução da Política Nacional de Resíduos Sólidos depende da participação efetiva da sociedade, seja através de simples ações como não jogar lixo no chão, separar os resíduos para a coleta seletiva municipal ou, de maneira mais efetiva, contribuindo para a não geração, redução, reutilização e reciclagem de resíduos sólidos. A separação prévia é uma obrigação, que instiga a população a contribuir na separação dos resíduos recicláveis e descartando adequadamente, conforme previsões legais.

A consolidação da Política Nacional de Resíduos Sólidos encontra diferentes objeções para seu avanço. Dentre elas está a carência de incentivos econômicos para empregar soluções ao 
processo de recolhimento, o reaproveitamento e/ou descarte, as dificuldades de logística, a carência de recursos humanos capacitados e a ausência de dados e informações para a gestão de resíduos sólidos.

Poder público e sociedade são importantes atores na fiscalização do setor empresarial, para que esse execute de fato sua parte na gestão de resíduos sólidos. Ações de conscientização contribuem com a redução da quantidade coletada pelos municípios, propiciam economia de recursos financeiros, geram menos poluentes, preservam o meio ambiente e garantem maior qualidade de vida a todos.

Finalmente acredita-se ter respondido ao problema de pesquisa bem como ao objetivo proposto. Como limitações da pesquisa têm-se o levantamento de percepções exclusivo dos associados da ASLORE, não sendo considerados outros envolvidos na cadeia da Logística Reversa, como catadores, cooperativas, recicladores, membros do acordo setorial ou mesmo da diretoria da Associação. Restringe-se, também, às ações de Logística Reversa nas categorias ambiental, econômica, legal e social de embalagens pós-consumo, conforme determina o Estatuto da ASLORE, não estando direcionado aos demais itens mencionados no Artigo 33 da Lei 12.305/10, que relaciona os materiais obrigados a estruturar e implementar sistemas de Logística Reversa (agrotóxicos, pilhas e baterias, pneus, óleos lubrificantes, seus resíduos e embalagens, lâmpadas fluorescentes, produtos eletroeletrônicos e seus componentes).

Como sugestão para pesquisas futuras entende-se que é válido aprofundar o entendimento sobre qual a razão de os associados atribuírem maior importância para determinados aspectos, pois nesta pesquisa objetivou-se apenas identificá-los. Quanto às perspectivas do impacto econômico, sugere-se a avaliação de técnicas de gestão ambiental, considerada a responsabilidade da organização em retornar o material colocado no mercado (enfatizando os itens obrigatórios previstas na Lei $12.305 / 10)$. Por fim, sugere-se aprofundar os conhecimentos a partir do conceito de institucionalismo.

\section{REFERÊNCIAS}

ALVES, R. R. (2016). Administração Verde: O caminho sem volta da sustentabilidade ambiental nas organizações. Rio de Janeiro: Elsevier.

ASSOCIAÇÃO BRASILEIRA DE EMBALAGENS - ABRE. (2019). São Paulo, SP. Disponível em: $<$ http://www.abre.org.br/setor/dados-de-mercado/dados-de-mercado/>. Acesso em: 20 jan. 2019.

BARTHOLOMEU, D. B.; CAIXETA-FILHO, J. V. (Orgs.) (2017). Logística Ambiental de Resíduos Sólidos. São Paulo: Atlas.

BRASIL. Decreto no 7.404, de 23 de dezembro de 2010. Regulamenta a Lei $n-12.305$, de 2 de agosto de 2010, que institui a Política Nacional de Resíduos Sólidos, cria o Comitê Interministerial da Política Nacional de Resíduos Sólidos e o Comitê Orientador para a Implantação dos Sistemas de Logística Reversa, e dá outras providências. Disponível em: 
<http://www.planalto.gov.br/ccivil_03/_ato2007-2010/2010/decreto/d7404.htm>. Acesso em: 19 mai. 2018.

BRASIL. Lei 12.305, de 02 de agosto de 2010. Política Nacional de Resíduos Sólidos. Institui a Política Nacional de Resíduos Sólidos; altera a Lei no 9.605, de 12 de fevereiro de 1998, e dá outras providências. Diário Oficial da União, 3 ago. de 2010. Disponível em: <http://www.planalto.gov.br/ccivil_03/_Ato2007-2010/2010/Lei/L12305.htm>. Acesso em: 05 fev. 2018.

BRASIL. Ministério do Meio Ambiente. Guia para elaboração dos planos de gestão de resíduos sólidos 2011. Disponível em: <http://www.mma.gov.br/estruturas/srhu_urbano/_arquivos/guia_elaborao_plano_de_gest o_de_resduos_rev_29nov11_125.pdf>. Acesso em: 06 set. 2017.

CARVALHO, M. A. (2008). Engenharia de embalagens: uma abordagem técnica do desenvolvimento de projetos de embalagem. São Paulo: Novatec.

CASTRO, A. G. de; POUZADA, A. S. (Coord.) (2003). Embalagens para a indústria alimentar. Lisboa: Instituto Piaget.

COLLINS, J.; HUSSEY, R. (2005). Pesquisa em Administração: um guia prático para alunos de graduação e pós-graduação. 2. ed. Porto Alegre: Bookman.

GEUEKE, Birgit; GROH, Ksenia; MUNCKE, Jane. Foodpackaging in the circular economy: Overview of chemical safety aspects for commonly. Journal of Cleaner Production, [S.I.], v. 193, p. 491 - 505, 2018. Disponível em: <www.sciencedirect.com/science/article/pii/S0959652618313325>. Acesso em: 26 jan. 2019.

HERNÁNDEZ, C. T.; MARINS, F. A. S.; CASTRO, R. C. (2012). Modelo de Gerenciamento da Logística Reversa. Revista Gestão \& Produção, São Carlos, v. 19, n. 3, p. 445-456. Disponível em: <http://www.scielo.br/pdf/gp/v19n3/01.pdf>. Acesso em: 19 mai. 2018.

LEITE, P. R. (2009). Logística Reversa: meio ambiente e competitividade. São Paulo: Pearson.

MARTINS JUNIOR, J. (2009). Como escrever trabalhos de conclusão de curso: instruções para planejar e montar, desenvolver, concluir, redigir e apresentar trabalhos monográficos e artigos. Petrópolis: Vozes.

MOTA, Suetônio. Introdução à Engenharia Ambiental. 3. ed. Rio de Janeiro: Abes, 2003.

MOURA, R. A.; BANZATO, J. M. (1997). Embalagem, unitização \& conteinerização. 2. ed. rev. e ampl. São Paulo: IMAM. (Série manual de logística; v. 3).

MWANZA, B.; MBOHWA, C.; TELUKDARIE, A. (2018). Strategies for the Recovery and Recycling of PlasticSolidWaste (PSW): A Focus on Plastic Manufacturing Companies. Procedia Manufactoring:15th Global Conference on Sustainable Manufacturing, [S.I.], v. 21, p. 686-693. Disponível em: <https://www.sciencedirect.com/science/article/pii/S2351978918302129>. Acesso em: 13 set. 2018. 
NASCIMENTO, V. F., et al. (2015). Evolução e desafios no gerenciamento dos resíduos sólidos urbanos no Brasil. Revista Ambiente \& Água, Taubaté, v.10, n.4, Taubaté, out./dez. Disponível

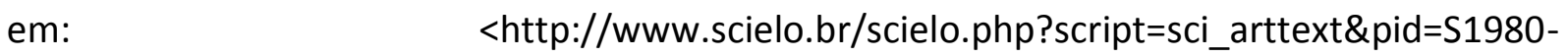
993X2015000400889\&lng=pt\&nrm=isso >. Acesso em: 19 mai. 2018.

OLIVEIRA, G. K. L. P. de. (2017). Tecnologias Verdes: mecanismos de efetivação da Política Nacional de Resíduos Sólidos aplicadas ao setor agrícola. 129 f. Dissertação (Mestrado em Direito Agrário) - Universidade Federal de Goiás, Goiânia, 04 abr. 2017.

RIBEIRO, D. V.; MORELLI, M. R. (2009). Resíduos sólidos: problema ou oportunidade? Rio de Janeiro: Interciência. 135 p.

SISTEMA NACIONAL DE INFORMAÇÕES SOBRE A GESTÃO DOS RESÍDUOS SÓLIDOS - SINIR. (2017). Brasília, DF. Disponível em: <http://sinir.gov.br/>. Acesso em: 01 set. 2017.

SLACK, N.; CHAMBERS, S.; JOHNSTON, R. (2009). Administração da Produção. 3. ed. São Paulo: Atlas.

SOCIEDADE PONTO VERDE. (2015). Disponível em: <https://www.pontoverde.pt/>. Acesso em: 14 out. 2018.

SOLER, F. D. (2014). Os acordos setoriais previstos na Lei Federal n. 12.305/2010 (Política Nacional de Resíduos Sólidos - PNRS): Desafios jurídicos para a implementação da logística reversa no Brasil. 2014. 124 f. Dissertação (Mestrado em Direito) - Pontífica Universidade Católica de São Paulo, São Paulo.

TRIVIÑOS, A. N. S. (1987). Introdução à Pesquisa em Ciência Sociais: a pesquisa qualitativa em educação. São Paulo: Atlas. 